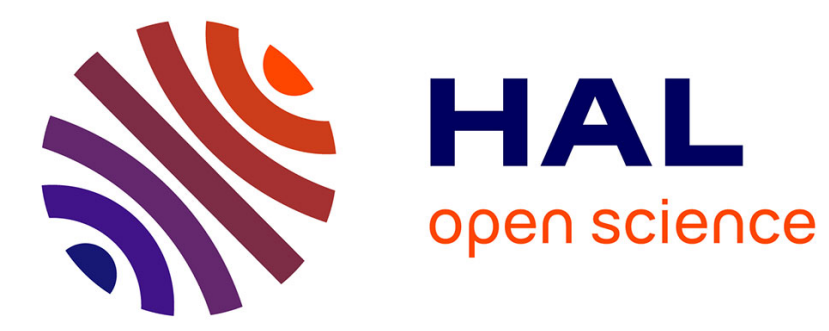

\title{
Requirements for Mobile Learning in Vocational Training in the Field of Mechanical Engineering \\ Adrian Wilke
}

\section{To cite this version:}

Adrian Wilke. Requirements for Mobile Learning in Vocational Training in the Field of Mechanical Engineering. 11th IFIP World Conference on Computers in Education (WCCE), Jul 2017, Dublin, Ireland. pp.104-113, 10.1007/978-3-319-74310-3_13 . hal-01762901

\section{HAL Id: hal-01762901 \\ https://hal.inria.fr/hal-01762901}

Submitted on 10 Apr 2018

HAL is a multi-disciplinary open access archive for the deposit and dissemination of scientific research documents, whether they are published or not. The documents may come from teaching and research institutions in France or abroad, or from public or private research centers.
L'archive ouverte pluridisciplinaire HAL, est destinée au dépôt et à la diffusion de documents scientifiques de niveau recherche, publiés ou non, émanant des établissements d'enseignement et de recherche français ou étrangers, des laboratoires publics ou privés. 


\title{
Requirements for Mobile Learning in Vocational Training in the field of Mechanical Engineering
}

\author{
Adrian Wilke \\ Paderborn University, Department of Computer Science, Germany \\ adrian.wilke@uni-paderborn.de
}

\begin{abstract}
Learning and working tasks in vocational education and training (VET) in the field of mechanical engineering comprise theoretical knowledge and practical activities, for instance, manufacturing a workpiece using a CNC turning machine. To clarify the requirements of these extensive tasks and the support by a mobile application, trainers of companies with training facilities were interviewed. The results of a qualitative content analysis with regard to application and task areas, communication patterns, learning materials, and expectations towards mobile learning are described in this article. Additionally, the resulting practical experiences and the expectations of trainers are included in an instructional design for the support of formal learning and working tasks in VET.
\end{abstract}

Keywords: Vocational Training, Mechanical Engineering, Mobile Learning, Requirements Analysis

\section{Introduction: The Domain of VET and Mobile Learning}

The dual system of vocational education and training (VET) in Germany takes place at two learning venues with training personnel of different specialization. In part-time vocational schools, the acquisition of theoretical knowledge is focused and supported by vocational teachers. In companies with training facilities, trainers give workplacerelated instructions in practical contexts [1]. The tasks of trainers include the planning, execution, and reflection of teaching and learning processes. They have to develop qualification opportunities, while the demands are constantly changing, e.g. due to changing expectations of apprentices or media habits. In order to meet such challenges, teaching and learning methods have to be adapted [2].

Today's adaptions to teaching and learning methods are often related to e-learning systems. The utilization of the internet, technology, and digital media opens various possibilities to handle learning tasks in VET. For instance, there are the distribution of contents, visualizations, interactions among people and systems, different ways of structuring contents, assessments, and the support for reflection [3]. However, an education system has to meet the requirements of the respective underlying domain.

In contrast to office jobs, in-company training in the field of mechanical engineering and metal-working takes place at different areas of work, e.g. at shop floor locations and office areas. Therefore, mobile devices are more suitable for the assistance of e-learning systems than desktop computers [4]. Another argument for the integration of a mobile learning approach for VET is the learning behavior of the 
target group of apprentices in the field of metal-working. They prepare for examinations at home, in training companies, in vocational schools, and partially in buses and trains [5].

There have been several academic works combining VET in the dual system, mechanical engineering, and mobile learning. The project Kompetenzwerkstatt (literal translation: competence workshop) focuses on analyzing and describing work processes. In this context, the six categories of digital media for task-oriented learning mentioned above were worked out [3]. Another approach in engineering education is competence snippets. These are so-called knowledge floaters, short media-supported units of learning, accessible via QR-codes or NFC [6]. The project KMU Smart Factory focuses on manufacturing processes and awareness of the following types of contexts: locations, learning-objects, devices, cooperation, time, action, and users [7, 8]. The Produktionslernsystem (PLS, production learning system) uses visualizations of, inter alia, vertices and directed edges to document workflows in the car industry [4].

This article is part of the research project Mobile Learning in Smart Factories (MLS), which focuses initial VET in the field of mechanical engineering and learning and working tasks. To assist the main focus groups of apprentices and trainers, a mobile application for context-sensitive learning in training companies and related learning scenarios are under development [9]. Starting with an initial draft specification, the development of the project parts of software, learning scenarios, and conducted workshops proceeds in parallel to a refinement of the requirements (see Fig. 1).

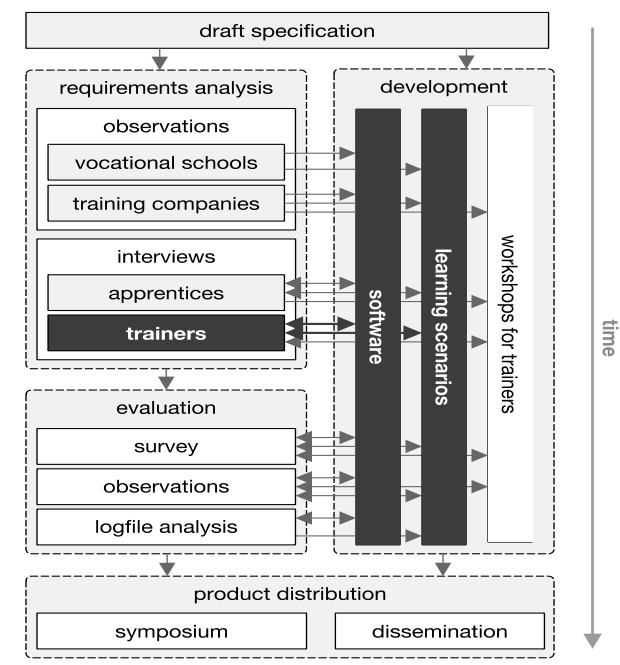

Fig. 1. Development process of the MLS project and focus of this article

In the first series of interviews, we asked apprentices for tasks and typical activities in their daily work, educational contents and materials in use, learning topics, and the usage of hardware and software in their learning environments. One result relating to learning activities in companies is the importance of practical tasks. The main 
activities of apprentices from the mechanical engineering sector (primarily in the training occupation of the metal cutting mechanic) are strongly related to actionoriented tasks in the context of work orders. At the beginning of work orders, trainers typically hand over mechanical drawings and instruct the apprentices to clarify necessary work procedures. Processing a work order takes place in six typical phases. Apprentices have to analyze the drawings, prepare a work plan for the production process, decide between alternatives within the production process, manufacture components, perform a quality control, and evaluate the results. The process consisting of these phases and the related learning materials can be supported by mobile devices and digital media to assist in issues of organization and self-regulated learning [5].

This basic research is part of the MLS requirements analysis. In our project, we interviewed trainers of companies with training facilities to refine the requirements and the development of the MLS software and learning scenarios. In this article, we focus on the investigation of the following research questions:

- Which fields of VET and mechanical engineering are suiting the targeted support with a mobile application from the trainer's point of view?

- Which tasks and activities of the current learning and working practice can be embedded in appropriate learning scenarios?

- How should possible technical features be implemented to assist in independent learning in VET?

\section{Methods: Interviews and Qualitative Content Analysis}

In this research, we conducted semi-structured interviews and carried out a qualitative content analysis of the transcribed interview contents. We visited five companies with mechanical engineering training facilities and interviewed nine trainers. (In four companies, respectively two trainers were interviewed.) The survey took place from May 2015 to May 2016. For the survey and analysis, we performed the following steps:

1. Preparation of the investigation by determining the research interests. These are everyday working practices in the apprenticeship, requirements for the support of VET by a mobile application, and related experiences of trainers.

2. Development of an interview guide with the following four main topics: requirements for mobile learning scenarios in vocational training (12 items), learning conditions and previous experiences of trainers (8 items), interests in technical systems (2 items), and expectations towards a developed system (2 items). For each of the 24 items, we prepared the following four types of questions: (a) Open-ended questions to introduce the area of interest, (b) a list of terms to check, if all relevant fields have been mentioned, (c) specific follow-up items to mention related fields of interest, and (d) optional control questions to keep up the flow of conversation.

3. We conducted semi-structured interviews using the developed interview guide. The conversations were audio recorded. 
4. The audio records were transcribed with support of student assistants. To ensure consistency, a set of simple transcription rules [10] was applied.

5. We performed a qualitative content analysis. Therefore, we chose the method of theme analysis [11]. As an initial category system, the interview guide with 24 questions was used. In a first iteration of the analysis, we refined the categories to a final set of 30 categories. Afterwards, each transcript was independently coded by two people. In this step, the people marked text parts consisting of questionanswer-pairs and assigned them to exactly one category. We chose this approach of coding instructions to maintain the contexts of the answers. Overall, 2,096 codings were assigned by two people. The coded segments were summarized per category.

6. We calculated the intercoder agreement [12] for each of the nine coded interview transcripts. This was done using the MAXQDA 12 software [13], the function "intercoder agreement", and the options "segment agreement" and "correlates $100 \%$ ". The arithmetical mean of the nine resulting values of Cohen's Kappa is $\kappa=$ 0.9167. This almost perfect agreement [14] is the result of pairing questions and answers and the following assignment of these pairs to exactly one of the predefined categories.

\section{Results: Expertise of Trainers}

To focus on the research questions, we describe the following topics: tasks and activities, communication among trainers and apprentices, task assignment, learning materials, and expectations of trainers towards mobile learning.

\subsection{Tasks and activities}

With regard to the underlying ordinance [15], skills, knowledge, and competences in the industrial metal occupations should be imparted in a process-related way. This has to be done in three and a half years. To investigate, how these formal requirements are currently implemented in companies, we asked the trainers for types of tasks occurring in their training. The interviewees described the following tasks.

In addition to the practical characteristics of training facilities in contrast to schools, the training in companies differs from the diverse scope of tasks in vocational and mainstream schools. After some basic training in metal working, where filing and drilling are practiced, all tasks are production-oriented and embedded in the structure of a complete action. This is often represented as a sequence of the phases: inform, plan, decide, implement, control, and evaluate. Whereas the tasks, or rather work orders, follow the same structure, they are arranged by increasing complexity and differ in the machining processes used (e.g. milling or turning). Typically, workpieces are firstly produced on conventional lathes and milling machines and afterwards on Computer Numerical Control (CNC) machines. Work orders mainly are didactically prepared learning tasks. Starting with simple workpieces, the level of difficulty increases. This is put into practice by increasing the number of tolerances and refining their thresholds. In other words, workpieces become more detailed. Another advanced task is the production of assemblies. Single components are produced and have to be assembled. Assemblies can be composed of 
components, which are produced using different machining processes. To complete such a task, milling and turning have to be mastered. In general, tasks are assigned in consideration of the individual learning progresses of apprentices. For high performing apprentices, tasks inspired by WorldSkills ${ }^{1}$ competitions can be assigned.

The described tasks in different companies are similar to each other, as they are composed of connected sub-tasks, which are well-known as the model of a complete action, or rather, the programmed instruction [16, 17]. Each sub-task contains separate objectives, prerequisites, and activities. A major requirement for the assistance by an e-learning system is to match these properties and support overall solution- and learning processes. For instance, every working task includes the creation of a production sheet [18]. This depends on the analysis of a mechanical drawing, which can be enriched with 3D representations [5] and produces data, which should be reused at the manufacturing stage. Learners can reuse created and provided data in various contexts and use it for work planning [3]. Mobility becomes another requirement for the described tasks, as apprentices sometimes have to leave their workplace locations, e.g. to consult reference books [5]. In some instances, they plan the production process at the office and work on machines at the shop floor. In such cases, mobile devices can provide opportunities to connect learning for work and learning at work by applying generic knowledge to solve immediate work problems [19].

\subsection{Communication and task assignment in the apprenticeship}

The use of mobile devices and technical systems offers various alternatives of interaction and collaboration. To gain an overview of the present communication patterns, we asked about communication among trainers and apprentices. The answers were often related to statements about the assignment of tasks and the use of mechanical drawings.

For all interviewed trainers, direct face-to-face communication is the most important channel for communication. On the one hand, this was explained due to the fact that trainers and apprentices are in immediate proximity during working hours. On the other hand, briefings for work orders take place on site, directly at the workspaces, right at machines. In this context, trainers frequently demonstrate work procedures on machines. Additionally, questions and discussions are also part of briefings. During the production, trainers inspect components and adjust the work progress, if it is necessary.

In addition to the importance of direct face-to-face communication, mechanical drawings are frequently mentioned. These are significant resources in the communication process and utilized for problem analysis and instructions. Additionally, order forms are considered important for the documentation.

As a result, regarding mobile learning in VET in the given domain and considering the trainers' view, the support of direct communication is not [sic] a required feature. Nevertheless, there can be advantages in supporting communication in the contexts of task assignment and feedback. For instance, apprentices have to document the execution of orders [15]. This has to be coordinated with trainers and is therefore a part of communication and the external evaluation by trainers. The documentation

1 WorldSkills: https://www.worldskills.org/ 
process can also become a part of the reflection process, e.g. in the form of an eportfolio of finished tasks [3].

\subsection{Learning materials}

Learning materials are an important factor in the apprenticeship. A crucial type of materials are mechanical drawings, which are used for the assignment, explanation, and discussion of tasks. Mechanical drawings are handed over and form the basis of verbal instructions. The drawings contain data about specifications such as dimensions, size tolerances, surfaces, and threads of workpieces and components of assemblies. In addition to the drawings, trainers give verbal instructions and clarify gaps in the following fields: the types of machining processes, machine tools to use, particularly important characteristics of tasks, guide times or deadlines, and the number of pieces to be manufactured. The most frequently used book is the Mechanical and Metal Trades Handbook [18], which is also permitted to be used in final examinations.

Even though the interviewed trainers are satisfied with the currently available learning materials, all interviewees stated that they would like to use additional materials. Regarding digital media and in contrast to print media, the adaptation of digital artifacts to the continuous, rapid modernization of production processes is more practicable. Additionally, digital representations have advantages of animated contents and mobility contrary to thick folders.

\subsection{Expectations of trainers towards mobile learning}

The expectations placed on an informatics system for VET address a broad range of aspects. Expectations, which are mentioned several times are the support of the training in general and the access to learning materials for apprentices. Expected advantages for trainers are a reduction of workload and a saving of time. These aspects would support the possibility of individual support of apprentices. Apprentices should benefit from the system for the duration of the entire apprenticeship. Altogether, the integration of a learning system has to achieve better work results.

A main advantage of digital media, which is mentioned by trainers, is visualization. The work with machines, which are not available locally, can be presented virtually, by using animations or videos. This is also the case for the understanding of internal parts of machines. Processes can be presented digitally, which avoids the need for disassembling machines. Additionally, data can be accessed nearby machines and other places of learning by the use of portable technical devices.

An important property of VET in training companies is independent learning. If a basic level of training is reached, apprentices should be able to work through tasks on their own. A digital learning system has to support them at the acquisition of related competences. This can be realized by providing relevant information for the solution of tasks, step-by-step instructions, assistance in self-assessment, or feedback of the current level of knowledge. A learning platform should be used complementary to existing procedures and solutions in VET.

For the function of trainers, the organization of tasks is important. On the one hand, this is assistance in the assignment of tasks. Depending on the current learning 
state and experiences of apprentices, trainers have to assign appropriate work orders in terms of complexity. On the other hand, the documentation of finished projects and treated contents is essential. For the evaluation of the learning progress of apprentices and the learning fields that have been covered, a digital system would be an added value.

\section{Conclusion and Outlook: Mobile Learning in VET}

We conclude this work with a summary of the main statements of trainers, which represent basic requirements for the investigated field, and present an approach for a mobile application to support VET and mechanical engineering.

\subsection{Summary and resulting requirements}

To recapitulate the interview results, we summarize the following aspects from the trainer's point of view:

- Regarding the support of trainers, a digital system should support the organization of task assignment and the documentation of work results.

- Tasks in VET and mechanical engineering are oriented to practical actions in production processes. They are often embedded in work orders, used in nearly the entire period of VET, and have a similar structure. Related sub-tasks contain their own objectives, prerequisites, and activities.

- Tasks should be processed by apprentices independently. Independent learning can be supported by step-by-step instructions, provision of materials matching the respective sub-tasks, and individual feedback. The most important learning materials are mechanical drawings and the Mechanical and Metal Trades Handbook [18].

- Direct face-to-face communication is an important factor, which has to be preserved. The underlying conditions in the visited companies are suitable, as contact persons in training facilities are reachable in the immediate vicinity.

These aspects, which were derived from the interviewed trainer's perspectives, represent basic requirements for the target group of trainers in the involved companies with regard to a mobile application in VET and the field of mechanical engineering.

In the following, we present a framework which aims to meet these requirements and which is currently being practically tested in eight training companies.

\subsection{An approach for a mobile application to support learning tasks in VET and mechanical engineering}

The current state of the instructional design for mobile learning in VET and mechanical engineering (see Fig. 2) is a refinement of the aspects of learning processes, learning materials, social assistance, and underlying conditions, such as teaching-learning-objectives [5]. Core of the MLS application is a domain-specific task pool, offering dedicated views for the roles of trainers and apprentices. Trainers are supported in the assignment of appropriate tasks by a filtering system, which is 
based on task properties (inter alia: year of training, conventional or CNC manufacturing, milling or turning, screw threads or slots). An integrated editor opens up the possibility to create new tasks or to customize existing tasks to meet companyspecific requirements.

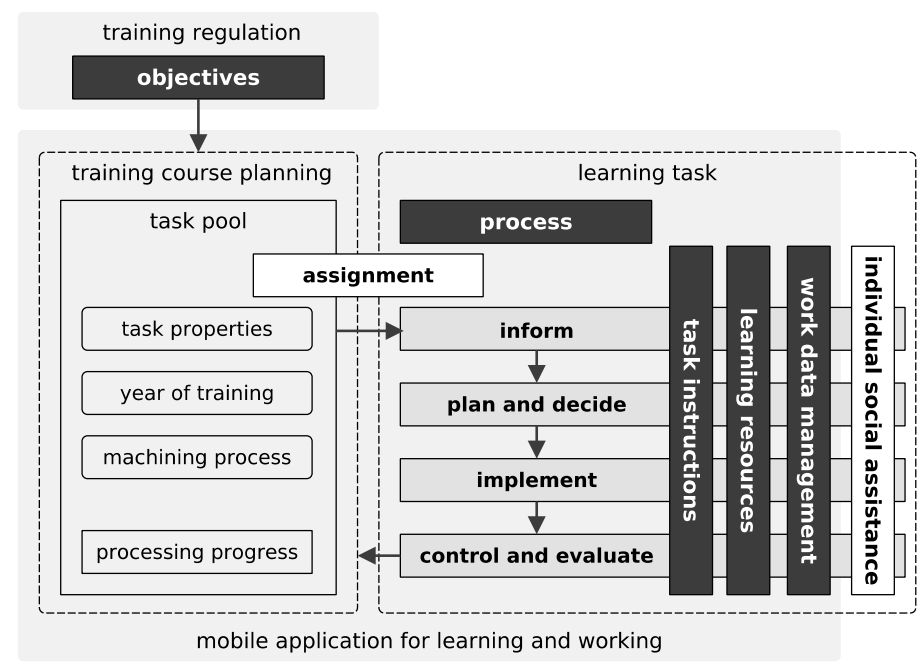

Fig. 2. Refined instructional design for independent learning tasks in vocational training and mechanical engineering embedded in a mobile application

The system aims to support apprentices in completing tasks independently. Therefore, every learning task is segmented into a sequence of sub-tasks, which are typically related to the phases "inform", "plan and decide", "implement", and "control and evaluate". Sub-tasks are built on each other to meet the respective prerequisites and learning objectives. Visually, they are represented as a combination of the current state in the overall task, brief instructions, required information, related learning materials, and interactive elements (see Fig. 3). Learning materials and interactive elements are frequently reused in different phases to access previously created work data. High-quality learning materials have been integrated through a cooperation with a publishing house [18] and the respective metadata was indexed to realize a fast access. The most important theoretical contents are embedded directly into sub-task views, others can be accessed using a search engine. At the beginning of a task, apprentices have to analyze at least one mechanical drawing. Drawings are provided as vector graphics and interactive $3 d$ representations. In the planning phase, apprentices have to prepare a digital production sheet. All entered data, notes, and learning materials can be reused afterwards during production, quality control and for reflection. The MLS application has been implemented as a web application to support the use of a broad diversity of mobile devices at different workplace locations and training companies. 


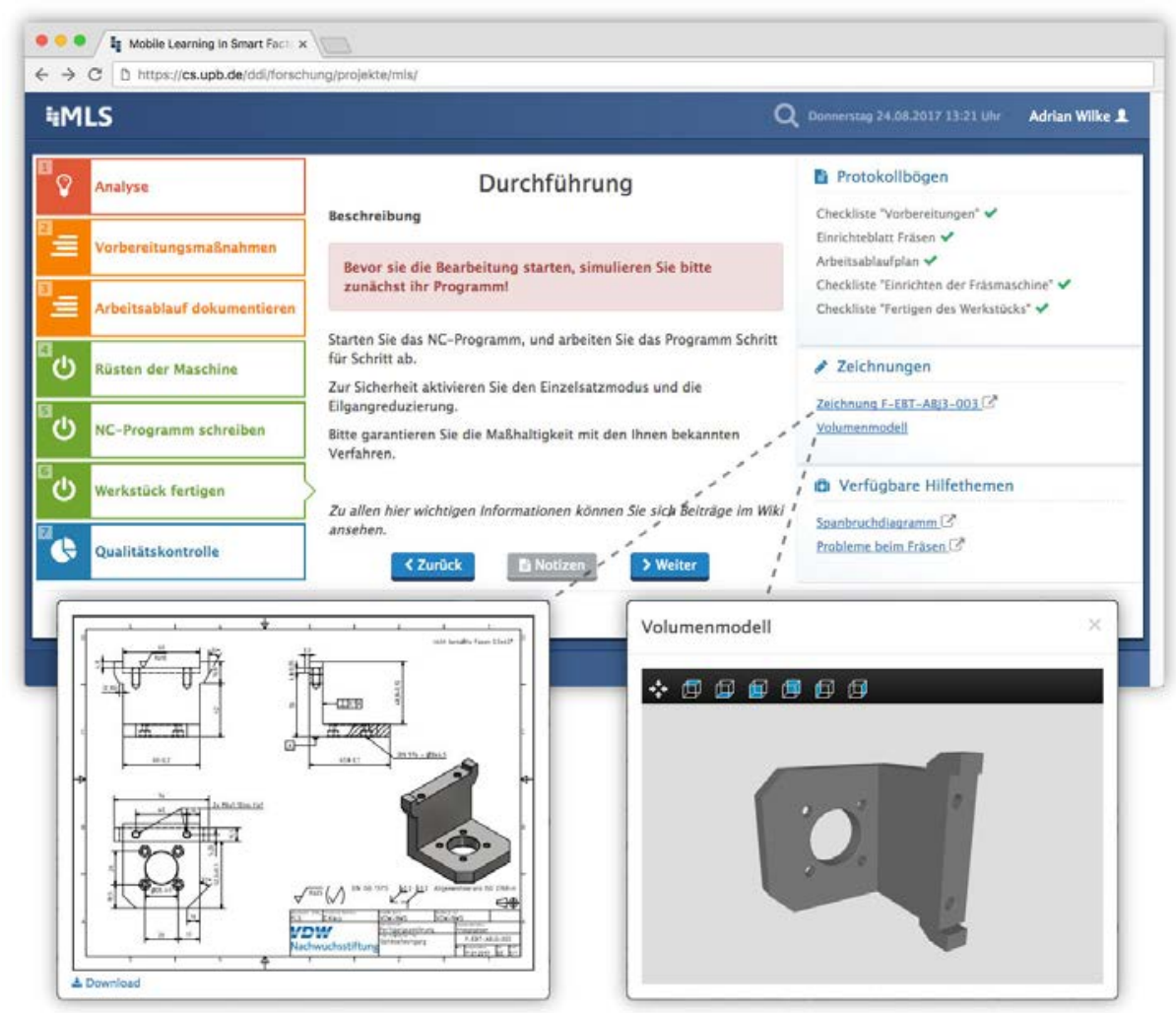

Fig. 3. Task view in MLS application, mechanical drawing, and interactive 3d representation

\section{Acknowledgements}

This work is part of the Mobile Learning in Smart Factories (MLS) project, which is funded by the German Federal Ministry of Education and Research (funding code: 01PD14009B) and implemented in cooperation with the non-profit company Nachwuchsstiftung Maschinenbau gGmbH.

\section{References}

1. Deissinger, T.: The German dual vocational education and training system as 'good practice'? Local Economy. 30, 557-567 (2015).

2. Hensen, K.A., Hippach-Schneider, U.: Supporting teachers and trainers for successful reforms and quality of VET - Germany (2016).

3. Howe, F., Staden, C.: Work Process Oriented and Multimedia-Based Learning in Vocational Education and Training. In: Gessler, M. and Freund, L. (eds.) Crossing Boundaries in Vocational Education and Training: Innovative Concepts for the 21st Century. pp. 25-32. Institut Technik und Bildung, Bremen (2015).

4. Engert, V.: Mobile Lernmöglichkeiten in der Automobilindustrie. In: de Witt, C. and Reiners, A. (eds.) Mobile Learning. pp. 205-217. Springer, Wiesbaden (2013). 
5. Wilke, A., Magenheim, J.: Requirements analysis for the design of workplace-integrated learning scenarios with mobile devices: Mapping the territory for learning in Industry 4.0. In: Proceedings of 2017 IEEE Global Engineering Education Conference. pp. 476-485. IEEE, Athens, Greece (2017). DOI: 10.1109/EDUCON.2017.7942890

6. Jaschke, S.: Mobile learning applications for technical vocational and engineering education: The use of competence snippets in laboratory courses and industry 4.0. In: Proceedings of ICL2014. pp. 605-608. IEEE (2014).

7. Sonderegger, U., Merschroth, C., Zimmermann, M.: Mobile Learning mit kontextbezogenen mobilen Diensten: Umsetzung in konkreten Szenarien und erste Erfahrungen. In: Rathmayer, S. and Pongratz, H. (eds.) DeLFI 2015 Pre-Conference Workshops Proceedings. pp. 222-231. München (2015).

8. Sonderegger, U., Zimmermann, M., Weber, K., Becker, B.: Mobile Learning mit kontextbezogenen mobilen Diensten in der "KMU Smart Factory": Szenarien und Lösungsansätze für Fertigungsprozesse. In: Rensing, C. and Trahasch, S. (eds.) DeLFI 2014 Pre-Conference Workshops Proceedings. pp. 229-239. Freiburg (2014).

9. Wilke, A., Kowalewski, M., Magenheim, J., Margaritis, M.: Facing the upcoming challenges in vocational training with mobile learning. In: Brodnik, A. and Lewin, C. (eds.) IFIP TC3 Working Conference "A New Culture of Learning: Computing and next Generations” Proceedings. pp. 405-406. Vilnius University, Lithuania (2015).

10. Dresing, T., Pehl, T., Schmieder, C.: Manual (on) Transcription. Transcription Conventions, Software Guides and Practical Hints for Qualitative Researchers. Marburg (2015).

11. Mayring, P.: Qualitative content analysis: theoretical foundation, basic procedures and software solution (2014).

12. Lombard, M., Snyder-Duch, J., Bracken, C.C.: Content Analysis in Mass Communication: Assessment and Reporting of Intercoder Reliability. Human Communication Research. 28, 587-604 (2002).

11. Mayring, P.: Qualitative content analysis: theoretical foundation, basic procedures and software solution (2014).

14. Landis, J.R., Koch, G.G.: The Measurement of Observer Agreement for Categorical Data. Biometrics. 33, 159 (1977).

15. Federal Institute for Vocational Education and Training: Ordinance on vocational education and training in the industrial mechanic (2007).

16. Deutsche Gesellschaft für Internationale Zusammenarbeit (GIZ) GmbH ed: Through Competence-Based to Employment-Oriented Education and Training (2013).

17. Bünning, F.: Approaches to Action Learning in Technical and Vocational Education and Training (TVET) (2007).

18. Heinzler, M., Fischer, U., Stephan, A., Paetzold, H., Kilgus, R., Näher, F., Gomeringer, R., Oesterle, S.: Mechanical and Metal Trades Handbook. Europa-Lehrmittel (2013).

19. Pimmer, C., Pachler, N.: Mobile Learning in the Workplace: Unlocking the Value of Mobile Technology for Work-Based Education. In: Ally, M. and Tsinakos, A. (eds.) Increasing Access through Mobile Learning. pp. 193-203. Vancouver (2014). 